\title{
Citrus Black Rot is Caused by Phylogenetically Distinct Lineages of Alternaria alternata
}

\author{
T. L. Peever, L. Carpenter-Boggs, L. W. Timmer, L. M. Carris, and A. Bhatia
}

First, second, and fourth authors: Department of Plant Pathology, Washington State University, Pullman 99164; and third and fifth authors: Citrus Research and Education Center, Institute of Food and Agricultural Sciences, University of Florida, 700 Experiment Station Rd., Lake Alfred 33850.

Accepted for publication 14 January 2005.

\begin{abstract}
Peever, T. L., Carpenter-Boggs, L., Timmer, L. W., Carris, L. M., and Bhatia, A. 2005. Citrus black rot is caused by phylogenetically distinct lineages of Alternaria alternata. Phytopathology 95:512-518.

Phylogenetic analysis revealed that isolates of Alternaria alternata causing black rot of citrus were associated with six well-supported evolutionary lineages. Isolates recovered from brown spot lesions on Minneola tangelo, leaf spot lesions on rough lemon, and healthy citrus tissue and noncitrus hosts were related closely to isolates from black-rotted fruit. Phylogenies estimated independently from DNA sequence data from an endopolygalacturonase gene (endoPG) and two anonymous regions of the

phylogeny, isolates from diverse ecological niches on citrus and noncitrus hosts were distributed in eight clades. Isolates from all lineages, regardless of ecological or host association, caused black rot in fruit inoculation assays, demonstrating that small-spored Alternaria isolates associated with different ecological niches on citrus and other plant hosts are potential black rot pathogens. These data also indicated that the fungi associated with black-rotted fruit do not form a natural evolutionary group distinct from other Alternaria pathogens and saprophytes associated with citrus. The use of the name A. citri to describe fungi associated with citrus black rot is not justified and it is proposed that citrus black rot fungi be referred to as A. alternata.
\end{abstract} genome (OPA1-3 and OPA2-1) had similar topologies, and phylogenetic analysis was performed on the combined data set. In the combined
Additional keywords: postharvest disease.
Alternaria spp. cause several diseases of citrus, including Alternaria brown spot of tangerine (Citrus reticulata Blanco), leaf and fruit spot of rough lemon (C. jambhiri Lush.) and Rangpur lime (Citrus $\times$ limonia Osbeck), mancha foliar de los citricos affecting Mexican lime (C. aurantiifolia (Christm.) Swingle), and black rot of fruit of several Citrus spp. (41). Species of Alternaria also commonly occur as saprophytes on all aboveground tissues of citrus trees and also may colonize citrus leaves as endophytes (T. L. Peever and L. W. Timmer, unpublished data). Alternaria black rot of citrus fruit is a significant postharvest problem that may appear in the field prior to harvest. The disease occurs most commonly on navel oranges $(C$. sinensis $(\mathrm{L}$.) Osbeck) in the field and on tangerines and their hybrids in storage (2). It is also a common problem on stored lemons (C. limon (L.) Burm.) and likely affects all citrus under the appropriate conditions. The disease is more prevalent in citrus production areas with Mediterranean climates characterized by cool, moist winters and hot, dry summers than in humid areas (1). Black rot occurs mostly as a core rot where the fungus invades and colonizes the columella. There is often little external evidence of infection except that the fruit is usually more intensely colored than healthy fruit. Infection may occur through wounds or natural openings in the stylar end of the fruit. Alternaria spp. also may form latent infections on the button (calyx and disc) and invade the columella when the fruit matures, resulting in black rot $(2,26)$. The disease is not controlled by common fungicides used in the packing house for control of other postharvest diseases such as Penicillium decays, stem-end rots, and anthracnose.

Corresponding author: T. L. Peever; E-mail address: tpeever@wsu.edu

DOI: 10.1094/PHYTO-95-0512

(C) 2005 The American Phytopathological Society
Black rot first was described in the early 1900s and the causal agent identified as Alternaria citri Ellis \& Pierce (3,23). A. citri also has been identified from various healthy citrus fruit, leaf, and twig tissues (31). Citrus black rot may be caused by more than one morphological species of Alternaria, including species other than A. citri $(6,12,31)$. Black rot isolates, as well as isolates causing brown spot of tangerine and leaf spot of rough lemon, historically have been assigned to A. citri based solely on their association with Citrus spp. hosts $(1,2,4,11,14)$. However, careful morphological examination or DNA sequence analyses were not employed to identify these fungi. Recently, 10 morphological species were described among brown spot and rough lemon leaf spot isolates sampled on a worldwide scale (35). No systematic study has been made of the species of Alternaria from black rotinfected fruit using either morphological or sequence-based characters, and the pathogenicity of isolates recovered from black-rotted citrus fruit rarely has been determined.

In a recent phylogenetic study of citrus-associated species of Alternaria using mitochondrial large subunit (mtLSU) and $\beta$ tubulin sequence data, all small- and catenulate-spored species formed a well-supported monophyletic lineage (21). This lineage included isolates that cause brown spot of tangerines and leaf spot of rough lemon, as well as saprophytic isolates associated with citrus and other plants. Citrus black rot isolates included in that study also were found in this lineage. Several well-supported, monophyletic clades could be distinguished within this smallspored citrus clade using more variable regions of the genome, such as an endopolygalacturonase gene (endoPG) and two anonymous genomic regions (OPA1-3 and OPA2-1) (21). Isolates from black-rotted citrus fruit were distributed throughout these phylogenies, suggesting that phylogenetically distinct lineages were able to cause black rot. A similar result was obtained previously with random amplified polymorphic DNA markers where black rot isolates were distributed throughout a phenogram of brown 
spot and rough lemon leaf spot isolates (18). The purpose of this study was to test the hypothesis that citrus black rot is caused by phylogenetically distinct lineages of A. alternata using phylogenetic analyses and pathogenicity tests. Our sample of isolates was obtained from black-rotted citrus fruit, leaf lesions on citrus, and healthy citrus leaf tissue from different geographic regions of the United States, as well as from other hosts. Our specific objectives were to determine (i) which citrus-associated morphospecies of Alternaria were capable of producing black rot, (ii) which morphospecies of Alternaria from other hosts were capable of producing black rot, and (iii) the phylogenetic relationships among isolates capable of producing black rot based on sequence data from the endoPG and two anonymous regions of the Alternaria genome.

\section{MATERIALS AND METHODS}

Isolate sampling. Isolates of small- and catenulate-spored citrus-associated Alternaria spp. were chosen to represent broad geographic, host, and ecological associations (Table 1). Eight isolates were obtained from citrus with visible symptoms of black rot, including one from grapefruit (C. paradisi Macfad.), six from sweet orange, and one from lemon. Our sample also included isolates from healthy leaf tissue, leaf spot lesions on rough lemon, and brown spot lesions on Minneola tangelo $(C$. reticulata $\times$ $C$. paradisi). This latter group included the morphospecies A. turkisafria Simmons, A. limoniasperae Simmons, A. tangelonis Simmons, A. citriarbusti Simmons, and A. dumosa Simmons (35). Isolates from Citrus spp. were coded according to the common name and tissue type of the host (Table 1). American Type Culture Collection (ATCC) isolate 58171 (4), identified as A. citri from king mandarin ( $C$. nobilis), was included as a black rot reference isolate. Closely related Alternaria spp. from other plant hosts were provided by collaborators (Table 1). Isolates not identified by E. G. Simmons were considered A. alternata sensu lato (21). All isolates were derived from single conidia and stored on sterile filter paper as previously described (18).

Production of conidial inoculum. For production of conidia used in pathogenicity tests, cultures of single-conidial isolates were grown on potato dextrose agar (PDA) for 5 days at $27^{\circ} \mathrm{C}$. Surface mycelium was removed by scraping with a sterile scalpel, and the underlying agar was cut into small pieces (1 to $2 \mathrm{~mm}^{2}$ ). In all, $\approx 50$ agar pieces were transferred to a plate of weak PDA ( $5 \mathrm{~g}$ of PD broth [Difco Laboratories, Detroit] plus $15 \mathrm{~g}$ of agar per liter of water) and incubated at $27^{\circ} \mathrm{C}$ under a 12 -h photoperiod for 3 to 5 days to promote conidial production. Conidia were collected from plates by scraping gently with a sterile glass rod and washing the dislodged conidia from the plates with

TABLE 1. Alternaria spp. isolates used in current study

\begin{tabular}{|c|c|c|c|c|c|c|}
\hline Species & Isolate & Code & Host & Tissue or disease & Source & Reference \\
\hline A. brassicicola ${ }^{\mathrm{a}}$ & 01-1a-s & brassicicola-1 & Cabbage & Black spot & L. Du Toit & $\ldots$ \\
\hline A. brassicicola ${ }^{\mathrm{a}}$ & $01-17 b-s$ & brassicicola-2 & Cabbage & Black spot & L. Du Toit & $\ldots$ \\
\hline A. solani $i^{\mathrm{a}}$ & A-solani & solani-1 & Potato & Early blight & L. Hutchison & $\ldots$ \\
\hline A. arborescens ${ }^{\mathrm{b}}$ & EGS 39-128 & arborescens-1 & Tomato & Stem canker & E. G. Simmons & 36 \\
\hline A. fragaria ${ }^{\mathrm{a}}$ & O-187 & fragaria-1 & Strawberry & Black spot & M. Yamamoto & 15,16 \\
\hline 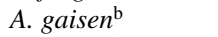 & EGS 37-1321 & gaisen-1 & Asian pear & Black spot & K. Kohmoto & 37 \\
\hline A. gaisen $^{\mathrm{b}}$ & EGS 90-0512 & gaisen-2 & Asian pear & Black spot & E. G. Simmons & 33,37 \\
\hline A. citri $^{\mathrm{a}}$ & ATCC 58171 & OR citri-1 & King mandarin & Black rot & $\mathrm{ATCC}^{\mathrm{c}}$ & 4 \\
\hline A. alternata s.l. ${ }^{\mathrm{a}}$ & $39-190$ & OR rot-1 & Sweet orange & Black rot & L. W. Timmer & 21 \\
\hline A. alternata s.l. ${ }^{\mathrm{a}}$ & A-citri-1 & OR rot-2 & Sweet orange & Black rot & L. W. Timmer & 21 \\
\hline A. alternata s.l. ${ }^{\mathrm{a}}$ & A-citri-2 & OR rot-3 & Tangerine & Black rot & L. W. Timmer & 21 \\
\hline A. alternata s.l. ${ }^{\mathrm{a}}$ & $39-189$ & OR rot-4 & Sweet orange & Black rot & L. W. Timmer & 21 \\
\hline A. alternata s.l. ${ }^{\mathrm{a}}$ & $\mathrm{UC}-2 \mathrm{~s}$ & OR rot-5 & Sweet orange & Black rot & J. Menge & 21 \\
\hline A. alternata s.l. ${ }^{\mathrm{a}}$ & UC-7s & LM rot-1 & Lemon & Black rot & J. Menge & 21 \\
\hline A. alternata s.l. ${ }^{\mathrm{a}}$ & $39-192$ & GR rot-1 & Grapefruit & Black rot & L. W. Timmer & 21 \\
\hline A. longipes ${ }^{\mathrm{b}}$ & EGS 30-033 & longipes-1 & Tobacco & Brown spot & E. G. Simmons & 29 \\
\hline A. citriarbusti ${ }^{\mathrm{b}}$ & SH-MIL-15s & MN spot-1 & Minneola tangelo & Brown spot & T. L. Peever & 18,35 \\
\hline A. tangelonis ${ }^{\mathrm{b}}$ & EV-MIL-2s & MN spot-2 & Minneola tangelo & Brown spot & T. L. Peever & 18,35 \\
\hline A. tangelonis ${ }^{\mathrm{b}}$ & SH-MIL-4s & MN spot-3 & Minneola tangelo & Brown spot & T. L. Peever & 18,35 \\
\hline A. turkisafria ${ }^{\mathrm{b}}$ & EGS 44-159 & MN spot-4 & Minneola tangelo & Brown spot & E. G. Simmons & 19,35 \\
\hline A. alternata s.l. ${ }^{\mathrm{a}}$ & SH3-4-8 NS2A & MN spot-5 & Minneola tangelo & Brown spot & T. L. Peever & $\ldots$ \\
\hline A. alternata s.l. ${ }^{\mathrm{a}}$ & SH3-4-8 OS3A & MN spot-6 & Minneola tangelo & Brown spot & T. L. Peever & $\ldots$ \\
\hline A. alternata s.l. ${ }^{\mathrm{a}}$ & EGS 45-002 & MN spot-7 & Minneola tangelo & Brown spot & Z. Solel & 19 \\
\hline A. dumosa $a^{\mathrm{b}}$ & EGS 45-007 & MN spot- 8 & Minneola tangelo & Brown spot & Z. Solel & 19,35 \\
\hline A. alternata s.l. ${ }^{\mathrm{a}}$ & EGS 45-008 & MN spot-9 & Minneola tangelo & Brown spot & Z. Solel & 19 \\
\hline A. alternata s.l. ${ }^{\mathrm{a}}$ & EGS 45-010 & MN spot-10 & Minneola tangelo & Brown spot & Z. Solel & 19 \\
\hline A. alternata s.l. ${ }^{\mathrm{a}}$ & EGS 45-062 & MN spot-11 & Minneola tangelo & Brown spot & S. H. Swart & 19,35 \\
\hline A. alternata s.l. ${ }^{\mathrm{a}}$ & BC2-RLR-22s & RL spot-1 & Rough lemon & Leaf spot & T. L. Peever & 18 \\
\hline A. alternata s.l. ${ }^{\mathrm{a}}$ & BC3-5-1 OS1A & RL spot-2 & Rough lemon & Leaf spot & T. L. Peever & $\ldots$ \\
\hline A. limoniasperae ${ }^{\mathrm{b}}$ & BC2-RLR-1s & RL spot-3 & Rough lemon & Leaf spot & T. L. Peever & 18,35 \\
\hline A. limoniasperae ${ }^{\mathrm{b}}$ & PR 325 & RL spot-4 & Rough lemon & Leaf spot & L. W. Timmer & 35,36 \\
\hline A. alternata s.l. ${ }^{\mathrm{a}}$ & HC3-6-14 NA2B & RL healthy-1 & Rough lemon & Healthy leaf tissue & T. L. Peever & $\ldots$ \\
\hline A. alternata s.l. ${ }^{\mathrm{a}}$ & HC3-6-14 OST2A & RL healthy-2 & Rough lemon & Healthy leaf tissue & T. L. Peever & $\ldots$ \\
\hline A. alternata s.l. ${ }^{\mathrm{a}}$ & HC3-9-8 NST1A & RL healthy-3 & Rough lemon & Healthy leaf tissue & T. L. Peever & $\ldots$ \\
\hline A. alternata s.l. ${ }^{\mathrm{a}}$ & EV3-1-2 NST3A & MN healthy-1 & Minneola tangelo & Healthy leaf tissue & T. L. Peever & $\ldots$ \\
\hline A. alternata s.l. ${ }^{\mathrm{a}}$ & EV3-1-4 NST2A & MN healthy-2 & Minneola tangelo & Healthy leaf tissue & T. L. Peever & $\ldots$ \\
\hline A. alternata s.l. ${ }^{\mathrm{a}}$ & EV3-1-5 OA3A & MN healthy-3 & Minneola tangelo & Healthy leaf tissue & T. L. Peever & $\ldots$ \\
\hline A. alternata s.l. ${ }^{\mathrm{a}}$ & EV3-1-7 OST1A & MN healthy-4 & Minneola tangelo & Healthy leaf tissue & T. L. Peever & $\ldots$ \\
\hline A. arbusti $^{\mathrm{b}}$ & EGS 91-129 & arbusti-1 & Asian pear & Black spot & E. G. Simmons & 37 \\
\hline A. infectoria ${ }^{\mathrm{b}}$ & EGS 27-193 & infectoria-1 & Wheat & Unknown & E. G. Simmons & 30 \\
\hline A. tenuissima ${ }^{\mathrm{b}}$ & EGS 34-015 & tenuissima-1 & Carnation & Unknown & E. G. Simmons & 34 \\
\hline A. alternata ${ }^{\mathrm{b}}$ & EGS 34-016 & alternata-1 & Peanut & Unknown & E. G. Simmons & $29,34,28$ \\
\hline
\end{tabular}

${ }^{a}$ Morphological species designation as per collector. A alternata s.1. = A. alternata sensu lato.

b Morphological species designation as per E. G. Simmons.

c ATCC $=$ American Type Culture Collection. 
sterile, distilled water into sterile $15-\mathrm{ml}$ centrifuge tubes. Conidia were filtered through three layers of sterile cheesecloth to remove large pieces of mycelium and hyphal fragments and then washed three times by centrifugation at $3,000 \times g$. Conidial concentrations were adjusted to $5 \times 10^{4}$ conidia/ml using a hemacytometer.

Pathogenicity assay. 'Hamlin' or 'Midsweet' sweet oranges (C. sinensis) were harvested from the field, washed with soap and water, surface disinfested with $95 \%$ ethanol, and placed in plastic chambers ( 30 by 20 by $10 \mathrm{~cm}$ ) to maintain high humidity. Calyces were removed from all fruit prior to inoculation. Fruit were inoculated by aseptically injecting $100 \mu \mathrm{l}$ of a conidial suspension $\left(5 \times 10^{4}\right.$ conidia/ml $)$ through the stem end of the fruit into the columella in the center of the fruit with a syringe. For each isolate in each experiment, 8 to 10 fruit were inoculated and incubated in the laboratory at 23 to $25^{\circ} \mathrm{C}$ for 21 days. Noninoculated fruit and inoculations with known black rot pathogens (OR citri-1 or GR rot-1) were included in each experiment as controls. Following incubation, fruit were cut in half and examined for black rot symptoms. Fruit were rated on a scale of 0 to 3, where $0=$ no symptoms, $1=1$ to $2 \mathrm{~cm}^{2}$ of black rot in the columella with typical black rot symptoms, 2 = approximately half the columella rotted, and $3=$ entire columella affected by black rot (Fig. 1).

Fungal culture and DNA extraction. Fungi were grown for 7 days in 2 -YEG liquid medium ( $10 \mathrm{~g}$ of dextrose and $2 \mathrm{~g}$ of yeast extract per liter) on a rotary shaker at $25^{\circ} \mathrm{C}$, and mycelium were collected and lyophilized as previously described (21). Genomic DNA was extracted from $50 \mathrm{mg}$ of lyophilized mycelium as described by Peever et al. (18) with modifications. One phenol/ chloroform/isoamyl alcohol (25:24:1, vol/vol/vol) extraction and one chloroform/isoamyl alcohol $(24: 1, \mathrm{vol} / \mathrm{vol})$ extraction were used. DNA concentrations were estimated visually in $0.7 \%$ agarose gels stained with ethidium bromide at $0.5 \mu \mathrm{g} / \mathrm{ml}$ by comparing band intensity with known quantities of uncut lambda DNA (Promega Corp., Madison, WI). DNA extractions were routinely diluted to 10 to $20 \mathrm{ng} / \mu \mathrm{l}$ in sterile distilled water for use as a polymerase chain reaction (PCR) template.

PCR and sequencing. EndoPG and two anonymous regions of the Alternaria genome, OPA1-3 and OPA2-1, were amplified and sequenced as described in Peever et al. (21), with modifications. EndoPG was amplified with primers EPG-specific (5'-TGTAAACCTTAGCGCCATCA-3') and EPG-3b (5'-TGTGCTACCATGGTTCTTTCC-3'). To obtain an OPA1-3 amplicon of convenient size for direct sequencing, primers OPA1-3Rb (5'AGCCACATGCTCTGGTTAGC-3') and OPA1-3L (5'-AGGCCCTTCCAATCCAT-3') were used. OPA2-1 was amplified with primers OPA2-1L (5'-TGCCGAGCTGTCAGATAATTG-3') and OPA2-1R (5'-GCCGAGCTGGTGGAGAGAGT-3'). Amplification products were visualized in $1.5 \%$ agarose gels (Life Technologies, Grand Island, NY) with HindIII/EcoRI digested lambda DNA (Promega Corp.) as size standards, stained with ethidium bromide at $0.5 \mu \mathrm{g} / \mathrm{ml}$, and visualized using a digital imaging system (UltraViolet Products, Upland, CA). Amplicons were purified using exonuclease and shrimp alkaline phosphatase (ExoSAP-it; USB Corp. Cleveland, $\mathrm{OH}$ ) according to the manufacturer's instructions. Amplicons were direct sequenced on each strand, with each sequence reaction containing 40 to $90 \mathrm{ng}$ of DNA, $500 \mathrm{nM}$ either forward or reverse primer, $4 \mu$ l of BigDye Terminator Cycle Sequencing Ready Reaction Mix (Applied Biosystems, Foster City, CA), and sterile distilled water to a total volume of $10 \mu \mathrm{l}$. Further processing and sequencing were completed as described by Peever et al. (21). All sequencing was performed in the Laboratory for Biotechnology and Bioanalysis, School of Molecular Biosciences, Washington State University.

Phylogenetic analysis. Consensus endoPG, OPA1-3, and OPA2-1 sequences each were aligned using ClustalX (40) and unrooted, maximum likelihood phylogenies were estimated independently for each sequence alignment and for the combined endoPG, OPA1-3, and OPA2-1 data set. Models of sequence evolution were tested for each alignment and model parameter estimates obtained for each alignment using MODELTEST 3.06 (24) implemented in PAUP 4.0 (38). The K80 model was selected for the endoPG data with equal base frequencies, a transition/ transversion ratio of 3.16 , and equal substitution rates among sites. For the OPA1-3 data, MODELTEST selected the HKY+G model with unequal base frequencies, a transition/transversion ratio of 2.04, unequal substitution rates among sites, and a gamma distribution shape parameter of 0.36 . The K80 model again was selected for the OPA2-1 data, with equal base frequencies, a transition/transversion ratio of 6.02 , and equal substitution rates among sites. For the combined data, MODELTEST selected the TIMef+I model with unequal base frequencies, equal transversion rates, two transition rates, proportion of invariable sites 0.83 , and equal substitution rates among sites. The reproducibility of phylogram topologies was estimated using 1,000 bootstrapped data sets generated using SEQBOOT in PHYLIP (8). The 1,000 data sets were used to estimate 1,000 phylograms in PHYML (9), using the selected substitution model, optimized base frequencies, transition/transversion ratios, and gamma shape parameters estimated from MODELTEST. Gaps were treated as unknown characters. For analysis of the combined data, the transition/transversion ratio was optimized during the analysis because the TIMef $+\mathrm{I}$ model does not have a single transition/transversion ratio. Majority-rule consensus trees were produced by CONSENSE in PHYLIP, and visualized with TREEVIEW (17). Maximum likelihood branch lengths for the consensus trees were determined using DNAML with the consensus tree as the user tree. Nodes with bootstrap values $>70 \%$ were considered significantly supported and used to infer clades. Phylogenies also were estimated for all genomic regions and the combined data set using neighbor-joining and maximum parsimony methods. Phylogenies estimated using these other methods produced phylograms identical in topology to the maximum likelihood analyses. Topological congruence of phylogenies estimated from each genomic region was evaluated using nonparametric incongruence length difference (ILD) tests (7) implemented in PAUP with invariant characters removed and 500 randomized partitions.
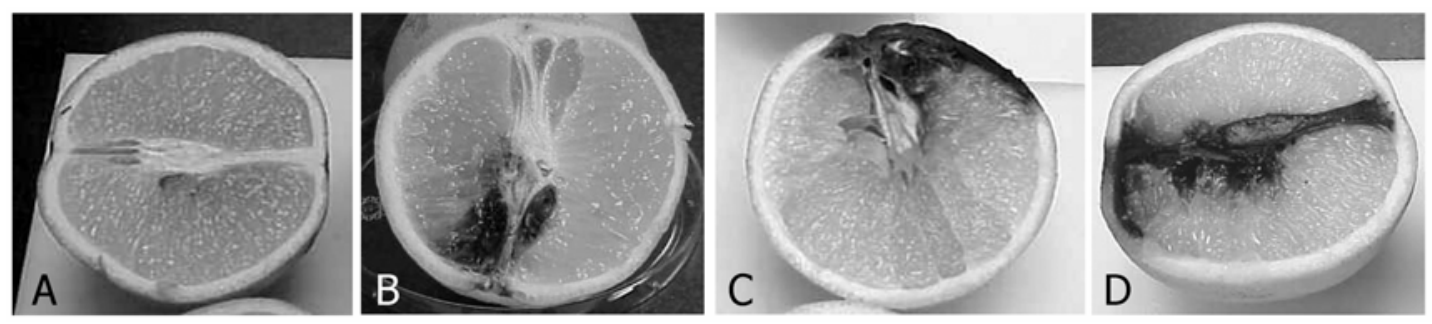

Fig. 1. Sweet orange (Citrus sinensis) inoculated with conidia of Alternaria alternata and evaluated 21 days postinoculation for symptoms of black rot. A, Unwounded and surface inoculated with isolate LM rot-1, black rot rating $=0 ; \mathbf{B}$, wounded and inoculated with isolate RL spot-4, black rot rating = 1.0; $\mathbf{C}$, wounded and inoculated with isolate LM rot-1, black rot rating $=2.0 ; \mathbf{D}$, wounded and inoculated with isolate OR citri-1, black rot rating $=3.0$. 


\section{RESULTS}

Pathogenicity. Black rot was produced on cvs. Hamlin or Midsweet oranges by all isolates tested (Fig. 1), except infectoria1, and brassicicola-1 and -2 (data not shown). Quantitative black rot severity scores of isolates from different clades, citrus hosts, and tissues were not significantly different (Fig. 1).

Phylogenetic analyses. No amplicons were obtained from isolates infectoria-1, brassicicola-1, brassicicola-2, arbusti-1, or solani-1 for any of the genomic regions, presumably due to significant sequence divergence in the priming sites. This result also was observed in a previous study (21). Amplification of endoPG using primers EPG-specific and EPG-3b produced 450-bp amplicons that were edited to $437 \mathrm{bp}$ before alignment. The endoPG phylogeny revealed six clades (Fig. 2). Amplification of anonymous region OPA1-3 using primers OPA1-3Rb and OPA1-3L yielded amplicons of $650 \mathrm{bp}$ that were edited to $560 \mathrm{bp}$ before alignment. Maximum likelihood analysis of OPA1-3 sequence data revealed six clades (Fig. 2). Amplification of anonymous region OPA2-1 using primers OPA2-1R and OPA2-1L yielded amplicons of $589 \mathrm{bp}$ that were edited to $571 \mathrm{bp}$ before alignment. Maximum likelihood analysis of OPA2-1 also revealed six clades (Fig. 2).

When phylogenies estimated from the three genomic regions were compared using the ILD test, the probability of obtaining a shorter tree than the sum of tree lengths for the original partition by chance was 0.002 , indicating significant incongruence among the data sets. Similarly, the three pairwise comparisons (OPA1-3 versus endoPG, OPA2-1 versus endoPG, and OPA1-3 versus OPA2-1) had $P$ values of $0.004,0.002$, and 0.002 , respectively, indicating topological differences among all three phylogenies. Tree lengths of the randomized data sets generally were only a few steps longer than the sums of tree lengths for each region estimated independently and only a few steps longer than would be declared significant at $P<0.05$ or $P<0.01$ (data not shown). All of the incongruence could be localized to four isolates that did not cluster consistently with the same isolates in each phylogeny (Fig. 2). For example, isolate gaisen-2 clustered with gaisen-1 and fragaria-1 in the endoPG and OPA2-1 phylogenies but not in the OPA1-3 phylogeny. Sequence data was confirmed by resequencing this isolate. Other isolates that appeared to be responsible for the majority of the incongruence included MN spot-10 and -11 and OR rot-4. These isolates also were resequenced to ensure that incongruence was not the result of sequencing error.

Visual comparisons of tree topologies estimated for each genomic region revealed broad congruence among clades and the phylogeny estimated from the combined analysis revealed eight clades (Fig. 2). Clade 1 consisted of fragaria-1 from strawberry and gaisen-1 from Japanese pear. Although the phylogenies estimated in this study were unrooted, we previously have demonstrated that this clade is basal to the citrus-associated isolates in rooted phylogenies (21). Five isolates, including longipes- 1 from tobacco, an isolate from healthy Minneola tissue (MN healthy-2), and three isolates from brown spot lesions on Minneola (MN spot-2, -3 , and -5 ) were found in combined clade 2 . Clade 3 contained three isolates from leaf spot lesions on rough lemon (RL spot-2, -3, and -4), a black rot isolate from sweet orange (OR citri-1), and tenuissima-1 from carnation. Clade 4 contained one from a brown spot lesion on Minneola (MN spot-11) and a black rot isolate from sweet orange (OR rot-4), and clade 5 contained another black rot isolate from sweet orange (OR rot-2) and arborescens- 1 from tomato. Clade 6 consisted of alternata- 1 from peanut, the black rot isolate GR rot-1 from grapefruit and $\mathrm{MN}$ spot-9, an isolate from a brown spot lesion on Minneola. Clade 7 contained isolates from a wide range of ecological niches and hosts, including healthy Minneola leaf tissue (MN healthy-4), leaf spots on rough lemon (RL spot-1), brown spot lesions on Minneola (MN spot-4, -6, and -7), brown spot lesions on Minneola
(MN spot-8), and black rot of orange and lemon (OR rot-5 and LM rot-1, respectively). Clade 8 contained an isolate from a brown spot lesion on Minneola (MN spot-1), isolates from healthy rough lemon and Minneola tissue (RL healthy-1, -2, and -3 and $\mathrm{MN}$ healthy- 1 and -3 , respectively), and black rot isolates from orange (OR rot-1 and -3).

An alternative to combining the data sets is to consider clades well resolved only in cases where the same clade is supported by all three phylogenies (43). If we take this approach, our data provides strong support for four clades among all isolates and three clades among the citrus-associated isolates (Fig. 2). The first clade supported by all three data sets is clade 1 of the combined analysis, which includes isolates gaisen-1, -2 , and fragaria- 1 . The second clade is clade 2 of the combined analysis, which includes isolates longipes-1; MN spot-2, -3 , and -5 ; and MN healthy-2. The third is clade 5 of the combined analysis, which includes isolates OR rot-2 and arborescens-1, and the fourth clade consists of clades $3,4,6,7$, and 8 of the combined analysis including the remainder of the isolates.

\section{DISCUSSION}

Citrus black rot is caused by closely related but phylogenetically distinct lineages of $A$. alternata. Citrus-associated isolates, including brown spot isolates from tangerine and tangerine hybrids, leaf spot isolates from rough lemon, isolates from healthy citrus leaf tissue, and isolates from black-rotted fruit, were distributed in eight clades in the combined endoPG, OPA1-3, and OPA2-1 phylogeny. All citrus-associated isolates as well as small-spored Alternaria spp. from other hosts caused black rot of orange and were found interspersed throughout the combined phylogeny, similar to the results of a previous study (21). Many of these same isolates previously were shown to cause brown spot of Minneola tangelo or leaf spot of rough lemon $(18,19)$. Isolates from black-rotted fruit were found in six combined clades clustered with isolates from other ecological niches on citrus and from unrelated plant hosts including peanut, tomato, and carnation. Isolates from these other hosts were able to cause black rot and were dispersed similarly throughout the combined phylogeny. Isolates recovered from black-rotted Minneola tangelo, mandarin, and navel orange in South Africa by Kang et al. (12) were examined morphologically and assigned to the morphospecies A. alternata (Fr.:Fr.) Keissl., A. pellucida Simmons, A. citri, A. tenuissima (Kunze:Fr.), and A. arborescens Simmons. These same isolates fell into four distinct clades based on phylogenetic analysis of a combined internal transcribed spacer and histone 3 data set. A. arborescens and A. tenuissima were polyphyletic, whereas A. pellucida, A. alternata, A. tenuissima, and A. citri were paraphyletic. Whether the phylogenetic lineages identified by Kang et al. (12) and in the current study should be recognized as species is controversial and depends upon the species concept employed. Many of the isolates studied here have been described as new species based on morphological criteria (35). However, a recent phylogenetic study of small-spored, citrus-associated Alternaria isolates revealed that many of the morphological species described by Simmons (35) were both paraphyletic and polyphyletic (21). It was concluded that there currently was insufficient information regarding the biology and ecology of these taxa to warrant species status and it was proposed that all citrusassociated isolates be referred to as A. alternata.

The name $A$. citri has been used to describe several smallspored Alternaria spp. associated with citrus, including toxinproducing, host-specific pathogens of leaves as well as black rot pathogens (14,42). Doidge (5), Ruehle (25), Kiely (13), and Pegg (22) all concluded that strains of Alternaria causing brown spot of tangerine and rough lemon leaf spot were morphologically identical to and conspecific with the fungi that cause black rot. However, these comparisons all were based on the morphology of 
detached conidia which has been deemed insufficient for accurate taxonomic differentiation of small-spored species of Alternaria $(32,35)$. Simmons (31) stated that most of the citrus-associated Alternaria fungi he has examined could not be placed in A. citri.
The present study did not include representative isolates of A. citri sensu Simmons; therefore, we do not know how many (if any) of our citrus-associated isolates would be morphologically classified as A. citri sensu Simmons. Based on a previous study

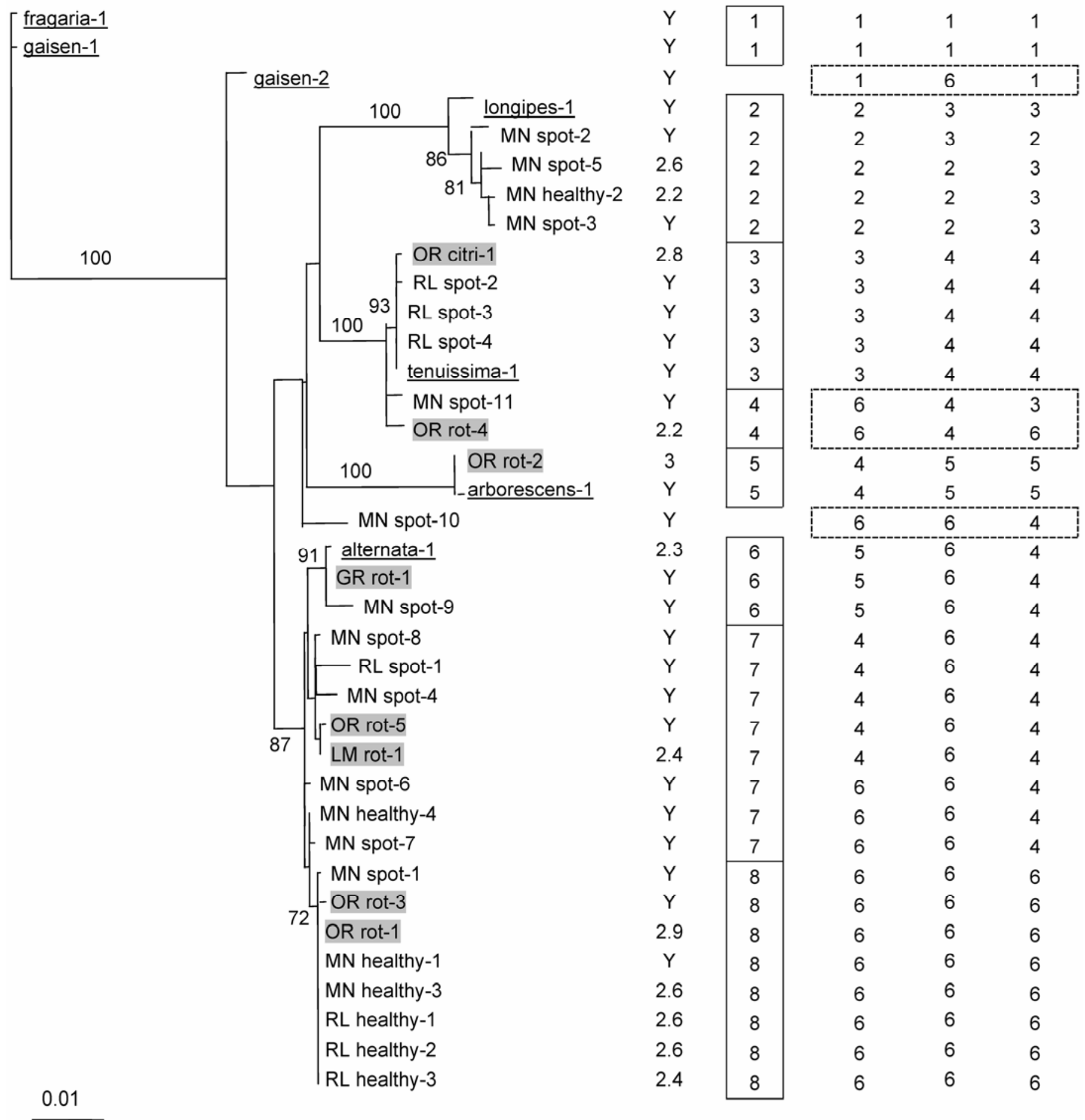

Fig. 2. Unrooted, combined endopolygalacturonase gene (endoPG), OPA1-3, and OPA2-1 phylogeny estimated among Alternaria alternata isolates sampled from citrus plus reference Alternaria spp. from other hosts. Phylogeny was estimated using maximum likelihood, and numbers at the major nodes indicate the percentage occurrence of the clade to the right of the node in 1,000 bootstrapped data sets. Only bootstrap values $>70 \%$ are shown. Branch lengths are proportional to the inferred amount of evolutionary change and the scale represents 0.01 nucleotide substitutions per site. Black-rot ratings (scale 0 to 3 ) are indicated with a numerical value or letter under the heading "Rot". A numerical value represents the mean black-rot rating from at least two independent inoculation experiments, whereas a "Y" indicates a rating of $\geq 1$ (significant black rot) from a single experiment. Isolates shaded in gray originally were isolated from black-rotted citrus fruit and underlined isolates are from noncitrus hosts. Clades inferred from the combined data set based on bootstrap values $>70 \%$ are numbered and boxed. Clades inferred for each data set independently based on bootstrap values $>70 \%$ are shown numbered at the right. Isolates responsible for incongruence among the three data sets are indicated by hatched boxes surrounding the clade designations. 
which tested the hypothesis that citrus-associated morphospecies were also phylogenetic species, some morphospecies mapped uniquely to phylogenetic clades, whereas others were paraphyletic and polyphyletic (21). In that study, black rot isolates fell into several distinct clades. In the current study, a larger sample of black rot isolates was tested and the same results were obtained. We speculate that $A$. citri sensu Simmons similarly represents a paraphyletic or polyphyletic assemblage of fungi; however, sequence data from representative isolates is required to test this hypothesis definitively. Currently, there is no phylogenetic or pathological evidence to justify the use of a distinct taxonomic category such as $A$. citri for the black rot pathogens. Citrus black rot pathogens should be referred to as A. alternata until such time that unique, easily diagnosable, and reproducible characters can be uniquely associated with phylogenetic lineages.

Isolates belonging to clade 2 of the combined analysis ("longipes clade") never have been recovered from rotted citrus fruit even though the pathogenicity assay indicated that these isolates can cause black rot when artificially inoculated. Our sample of isolates from black-rotted fruit was relatively small (eight isolates) and it is possible that isolates from the longipes clade were not found simply due to incomplete sampling. An alternative hypothesis is that isolates from this phylogenetic lineage lack ecological competence, which might prevent them from becoming black rot pathogens in citrus groves or the packing house. It is possible that they are less competitive colonizers of citrus fruit or of the citrus phylloplane or less aggressive colonizers of wounds in citrus fruit. Although none of the isolates recovered from black-rotted fruit fell into the longipes clade, isolates from this clade are the most common brown spot pathogens found in Florida (20). A. infectoria Simmons and A. brassicicola (Schwein.) Wiltshire were unable to cause black rot in the pathogenicity assay and these species never have been recovered from blackrotted citrus tissue. In a phylogenetic study of Alternaria spp. associated with black rot of tangelo in South Africa, Kang et al. (12) found that $A$. infectoria was associated with core rot of apple but not with black rot of citrus. We speculate that differences in the production of extracellular enzymes such as endo- and exopolygalacturonases or other degradative enzymes may be responsible for the lack of pathogenicity of A. infectoria and A. brassicicola on citrus fruit. A detailed comparison of the extracellular enzymes produced by these species with those produced by A. alternata might suggest some interesting hypotheses to test in future research.

The experimental design employed in this study allowed us to determine qualitative but not quantitative differences in ability to cause black rot. All small-spored Alternaria spp., including both citrus-associated isolates and isolates from other hosts, were able to cause black rot. It is possible that quantitative differences in black rot exist among isolates from different sources and phylogenetic lineages; however, a more quantitative assay is required to determine this. Quantitative differences in ability to cause black rot may be interesting biologically because they may reflect differences in the production of extracellular, degradative enzymes $(27,39)$. However, the economic significance of such quantitative differences in black rot is questionable because even low levels of infection (rated as 1 or higher in our assay) are sufficient to make the fruit unsaleable. Isshiki et al. $(10,11) \mathrm{mu}-$ tated the endoPG in both a rough lemon leaf spot isolate (PR325) and a black rot isolate (ATCC 58171) of A. alternata. The endoPGs in these strains were $99.6 \%$ identical, yet mutation of the gene resulted in complete loss of endoPG activity, suggesting that these fungi have only a single copy of this gene. Mutation of endoPG in strain PR325 had no effect on the ability of this strain to colonize leaf tissue but did significantly reduce black rot pathogenicity. Black rot pathogenicity was reduced for both ATCC 58171 and PR325, although both still had some ability to cause disease. These data indicate that the ability to cause black rot by small- and catenulate-spored isolates of A. alternata may be primarily controlled by the production of endoPG and support the conclusions reached herein that all isolates of A. alternata, regardless of host or ecological or phylogenetic association, appear to be potential black-rot pathogens.

\section{LITERATURE CITED}

1. Brown, G. E., and Eckert, J. W. 2000. Alternaria rot. Page 37 in: Compendium of Citrus Diseases. L. W. Timmer, S. M. Garnsey, and J. H. Graham, eds. The American Phytopathological Society, St. Paul, MN.

2. Brown, G. E., and McCornack, A. A. 1972. Decay caused by Alternaria citri in Florida citrus fruit. Plant Dis. Rep. 56:909-912.

3. Cobb, N. A. 1903. Letters on the diseases of plants-Alternaria of the citrus tribe. Agric. Gaz. N. S. W. 14:955-986.

4. Cotty, P. J., and Misaghi, I. J. 1984. Zinniol production by Alternaria species. Phytopathology 74:785-788.

5. Doidge, E. M. 1929. A study of some Alternarias infecting citrus in South Africa. Union S. Afr. Dep. Agric. Sci. Bull. 69:1-29.

6. Doidge, E. M., Bottomley, A. M., van der Plank, J. E., and Pauer, G. D. 1953. A revised list of plant diseases in South Africa. S. Afr. Dep. Agric. Sci. Bull. 346:1-122.

7. Farris, J. S., Kallersjo, M., Kluge, A. G., and Bult, C. 1994. Testing significance of congruence. Cladistics 10:315-319.

8. Felsenstein, J. 1993. PHYLIP (Phylogeny Inference Package), 3.6a2 ed. University of Washington, Seattle.

9. Guindon, S., and Gascuel, O. 2003. A simple, fast, and accurate algorithm to estimate large phylogenies by maximum likelihood. Syst. Biol. 52:696704.

10. Isshiki, A., Akimitsu, K., Nishio, K., Tsukamoto, M., and Yamamoto, H. 1997. Purification and characterization of an endopolygalacturonase from the rough lemon pathotype of Alternaria alternata, the cause of citrus brown spot disease. Physiol. Mol. Plant Pathol. 51:155-167.

11. Isshiki, A., Akimitsu, K., Yamamoto, M., and Yamamoto, H. 2001. Endopolygalacturonase is essential for citrus black rot caused by Alternaria citri but not brown spot caused by Alternaria alternata. Mol. PlantMicrobe Interact. 14:749-757.

12. Kang, J.-C., Crous, P. W., Mchau, G. R. A., Serdani, M., and Song, S.-M. 2002. Phylogenetic analysis of Alternaria spp. associated with apple core rot and citrus black rot in South Africa. Mycol. Res. 106:1151-1162.

13. Kiely, T. B. 1964. Brown spot of Emperor mandarin. Agric. Gaz. NSW 75:854-856

14. Kohmoto, K., Scheffer, R. P., and Whiteside, J. O. 1979. Host-selective toxins from Alternaria citri. Phytopathology 69:667-671.

15. Kusaba, M., and Tsuge, T. 1997. Mitochondrial DNA variation in hostspecific toxin-producing pathogens in the genus Alternaria. Ann. Phytopathol. Soc. Jpn. 63:463-469.

16. Maekawa, N., Yamamoto, M., Nishimura, S., Kohmoto, K., Kuwada, M., and Watanabe, Y. 1984. Studies on host-specific AF-toxins produced by Alternaria alternata strawberry pathotype causing Alternaria black spot of strawberry (1): Production of host-specific toxins and their biological activities. Ann. Phytopathol. Soc. Jpn. 50:600-609.

17. Page, R. D. M. 1996. TREEVIEW: An application to display phylogenetic trees on personal computers. Comput. Appl. Biosci. 12:357-358.

18. Peever, T. L., Canihos, Y., Olsen, L., Ibanez, A., and Liu, Y.-C. 1999. Population genetic structure and host specificity of Alternaria spp. causing brown spot of Minneola tangelo and rough lemon in Florida. Phytopathology 89:851-860.

19. Peever, T. L., Ibanez, A., Akimitsu, K., and Timmer, L. W. 2002. Worldwide phylogeography of the citrus brown spot pathogen, Alternaria alternata. Phytopathology 92:794-802.

20. Peever, T. L., Olsen, L., Ibanez, A., and Timmer, L. W. 2000. Genetic differentiation and host specificity among populations of Alternaria spp. causing brown spot of grapefruit and tangerine $\times$ grapefruit hybrids in Florida. Phytopathology 90:407-414.

21. Peever, T. L., Su, G., Carpenter-Boggs, L., and Timmer, L. W. 2004. Molecular systematics of citrus-associated Alternaria species. Mycologia 96:119-134.

22. Pegg, K. G. 1966. Studies of a strain of Alternaria citri Pierce, the causal organism of brown spot of Emperor mandarin. Qld. J. Agric. Anim. Sci. 23:15-28.

23. Pierce, N. B. 1902. Black rot of oranges. Bot. Gaz. 33:234-235.

24. Posada, D., and Crandall, K. A. 1998. MODELTEST: Testing the model of DNA substitution. Bioinformatics 14:817-818.

25. Ruehle, G. D. 1937. A strain of Alternaria citri Ellis and Pierce causing a leaf spot of rough lemon in Florida. Phytopathology 27:863-865.

26. Schiffmann-Nadel, M., Waks, J., Gutter, Y., and Chalutz, E. 1981. Alternaria rot of citrus fruit. Proc. Int. Soc. Citricult. 2:791-793. 
27. Shieh, M.-S., Brown, R. L., Whitehead, M. P., Cary, J. W., Cotty, P. J., Cleveland, T. E., and Dean, R. A. 1997. Molecular genetic evidence for the involvement of a specific polygalacturonase, $P 2 c$, in the invasion and spread of Aspergillus flavus in cotton bolls. Appl. Environ. Microbiol. 63:3548-3552.

28. Simmons, E. G. 1967. Typification of Alternaria, Stemphylium, and Ulocladium. Mycologia 59:67-92.

29. Simmons, E. G. 1981. Alternaria themes and variations. Mycotaxon $13: 16-34$

30. Simmons, E. G. 1986. Alternaria themes and variations (22-26). Mycotaxon 25:287-308.

31. Simmons, E. G. 1990. Alternaria themes and variations (27-53). Mycotaxon 37:79-119.

32. Simmons, E. G. 1992. Alternaria taxonomy: Current status, viewpoint, challenge. Pages 1-35 in: Alternaria: Biology, Plant Diseases and Metabolites. J. Chelkowski and A. Visconti, eds. Elsevier, Amsterdam.

33. Simmons, E. G. 1993. Alternaria themes and variations (63-72). Mycotaxon 48:91-107.

34. Simmons, E. G. 1995. Alternaria themes and variations (112-144). Mycotaxon 55:55-163.

35. Simmons, E. G. 1999. Alternaria themes and variations (226-235)-
Classification of citrus pathogens. Mycotaxon 70:263-323

36. Simmons, E. G. 1999. Alternaria themes and variations (236-243)-Hostspecific toxin producers. Mycotaxon 70:325-369.

37. Simmons, E. G., and Roberts, R. G. 1993. Alternaria themes and variations (73). Mycotaxon 48:109-140.

38. Swofford, D. L. 1998. PAUP*: Phylogenetic analysis using parsimony (* and other methods), $4.0 \mathrm{~b} 10$ ed. Sinauer Associates, Sunderland, MA.

39. Ten-Have, A., Mulder, W., Visser, J., and van Kan, J. A. L. 1998. The endopolygalacturonase gene Bcpgl is required for full virulence of Botrytis cinerea. Mol. Plant-Microbe Interact. 11:1109-1016.

40. Thompson, J. D., Gibson, T. J., Plewniak, F., Jeanmougin, F., and Higgins, D. G. 1997. The ClustalX windows interface: Flexible strategies for multiple sequence alignment aided by quality analysis tools. Nucleic Acids Res. 24:4876-4882.

41. Timmer, L. W., Peever, T. L., Solel, Z., and Akimitsu, K. 2003. Alternaria diseases of citrus-novel pathosystems. Phytopathol. Mediterr. 42:99112.

42. Whiteside, J. O. 1976. A newly recorded Alternaria-induced brown spot disease on Dancy tangerines in Florida. Plant Dis. Rep. 60:326-329.

43. Wiens, J. J. 1998. Combining data sets with different phylogenetic histories. Syst. Biol. 47:568-581. 